\title{
The influence of hepatitis $\mathrm{C}$ virus infection on $\mathrm{H} 1$ antihistamine treatment in urticaria patients
}

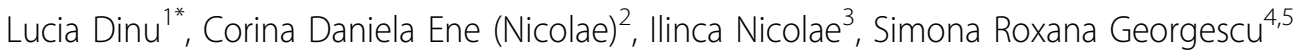 \\ From The 10th Edition of the Scientific Days of the National Institute for Infectious Diseases "Prof Dr Matei \\ Bals" \\ Bucharest, Romania. 15-17 October 2014
}

\section{Background}

Considerable evidence indicates that, in addition to antiallergic effect, several H1-antihistamines also possess antiinflammatory properties. The anti-inflammatory activity of $\mathrm{H} 1$ antihistamine treatment in urticaria patients is based on the capacity of H1-antihistamines to inhibit the release of chemical mediators from mast cells and basophiles, to regulate the chemotaxis of neutrophils and eosinophils, to increase eosinophils apoptosis and to reduce the expression of the adhesion molecules. Viral hepatic infections may affect the efficacy of $\mathrm{H} 1$ antihistamines probably interfering with their hepatic metabolism through cytochrome P450 system. We proposed to analyze the effect of hepatitis $\mathrm{C}$ virus (HCV) infection on the therapeutic efficacy of $\mathrm{H} 1$ antihistamines in urticaria patients.

\section{Methods}

The study included 37 acute and chronic spontaneous urticaria patients divided into two groups $(\mathrm{A}, \mathrm{B})$ depending on the associated HCV infection. Group A consisted of 30 urticaria patients without $\mathrm{HCV}$ infection and group B included 7 urticaria patients associating $\mathrm{HCV}$ infection. The experimental analysis targeted the dynamic of urinary histamine level (spectrofluorimetric method) depending on the Urticaria Activity Score (UAS) and C-reactive protein (CRP) level in patients with urticaria, during the treatment with $\mathrm{H} 1$-antihistamines. The clinical and paraclinical evaluations were done at the study entry and at 2 weeks after initiating the H1-antihistamine treatment.

\section{Results}

We obtained much stronger correlations between urinary histamine level and UAS, respectively CRP, for patients in group A $(r=0.924, p<0.05$, respectively $\mathrm{r}=0.548$, $\mathrm{p}<0.05$ at study entry and $\mathrm{r}=0.511, \mathrm{p}<0.05$, respectively $\mathrm{r}=0.286, \mathrm{p}<0.05$ after two weeks of $\mathrm{H} 1$-anti histamine treatment) comparing to those in group $\mathrm{B}(\mathrm{r}=0.836$, $\mathrm{p}<0.05$, respectively $\mathrm{r}=0.491, \mathrm{p}<0.05$ at study entry and $\mathrm{r}=0.484, \mathrm{p}<0.05$, respectively $\mathrm{r}=0.265, \mathrm{p}<0.05$ after two weeks of $\mathrm{H} 1$-anti histamine treatment) at both times of the assessment.

\section{Conclusion}

$\mathrm{HCV}$ infection reduces the anti-inflammatory effect of $\mathrm{H} 1$-antihistamines in urticaria patients.

\section{Authors' details}

'Department of Dermatology, MedLife Clinic, Bucharest, Romania. ${ }^{2}$ Department of Pharmacology, Carol Davila University of Medicine and Pharmacy, Bucharest, Romania. ${ }^{3}$ Department of Research, Clinical Hospital of Infectious and Tropical Diseases "Dr. Victor Babeș", Bucharest, Romania. ${ }^{4}$ Department of Dermatology, Carol Davila University of Medicine and Pharmacy, Bucharest, Romania. ${ }^{5}$ Department of Dermatology, Clinical Hospital of Infectious and Tropical Diseases "Dr. Victor Babeş", Bucharest, Romania.

Published: 15 October 2014

doi:10.1186/1471-2334-14-S7-P70

Cite this article as: Dinu et al:: The influence of hepatitis $C$ virus infection on $\mathrm{H} 1$ antihistamine treatment in urticaria patients. $B M C$ Infectious Diseases 2014 14(Suppl 7):P70.

* Correspondence: luciapesca@yahoo.com

'Department of Dermatology, MedLife Clinic, Bucharest, Romania

Full list of author information is available at the end of the article 